\title{
Entre partidas e chegadas: as possibilidades da mobilidade acadêmica para a formação inicial em Educação Física
}

\section{RESUMO}

O presente estudo objetivou analisar as contribuições que a mobilidade estudantil internacional pode proporcionar para a formação inicial, identificando ainda as principais motivações e os desafios encontrados pelos estudantes durante o período no exterior. Participaram do estudo 16 estudantes dos cursos de licenciatura e bacharelado em Educação Física da Universidade Federal de Pelotas/RS, que responderam a um questionário semiestruturado enviado de forma online. Os resultados mostraram que a vontade de conhecer um país diferente, o incentivo de professores e a busca por qualificação profissional foram os principais motivos de realização da mobilidade. As principais dificuldades encontradas foram o atendimento da burocracia do edital ou problemas familiares/financeiros enfrentados. Com relação às principais contribuições para a formação destacam-se o conhecimento de novas e diferentes culturas, a estrutura qualificada usufruída na universidade estrangeira, e o estabelecimento de redes de colaboração científica junto aos professores e grupos de pesquisa no exterior.

PALAVRAS-CHAVE: Ensino superior;

Internacionalização; Formação
José Antonio Bicca Ribeiro

Doutor em Educação Física

Universidade Federal de Pelotas, Escola Superior de Educação Física (ESEF/UFPel),

Pelotas, Brasil

jantonio.bicca@gmail.com

(1) https://orcid.org/0000-0002-1638-6687

Mariângela da Rosa Afonso

Doutora em Educação

Universidade Federal de Pelotas, Escola Superior de Educação Física (ESEF/UFPel),

Pelotas, Brasil

mrafonso.ufpel@gmail.com

(1) https://orcid.org/0000-0002-8853-719X 


\title{
Between departures and arrivals: the possibilities of student mobility for initial training in Physical Education
}

\begin{abstract}
The present study aimed to analyze the contributions that international student mobility can provide for initial training, also identifying the main motivations and challenges encountered by students during the period abroad. Sixteen students from undergraduate and bachelor's degrees in Physical Education from the Federal University of Pelotas/RS participated in the study, who answered a semi-structured questionnaire sent online. The results showed that the desire to get to know a different country, the encouragement of teachers and the search for professional qualification were the main reasons for achieving mobility. The main difficulties encountered were meeting the bureaucracy of the public notice or family/financial problems faced. Regarding the main contributions to training, the knowledge of new and different cultures, the qualified structure enjoyed at the foreign university, and the establishment of networks of scientific collaboration with professors and research groups abroad stand out.
\end{abstract}

KEYWORDS: Higher education; Internationalization; Formation

\section{Entre salidas y llegadas: las posibilidades de movilidad académica para la formación inicial en Educación Física}

\section{RESUMEN}

El presente estudio tuvo como objetivo analizar los aportes que la movilidad de estudiantes internacionales puede brindar para la formación inicial, identificando también las principales motivaciones y desafíos que encuentran los estudiantes durante el período en el extranjero. Participaron del estudio dieciséis estudiantes de pregrado y bachillerato en Educación Física de la Universidad Federal de Pelotas/RS, quienes respondieron un cuestionario semiestructurado enviado en línea. Los resultados mostraron que el deseo de conocer un país diferente, el estímulo del profesorado y la búsqueda de la cualificación profesional fueron los principales motivos para lograr la movilidad. Las principales dificultades encontradas fueron afrontar la burocracia del aviso público o los problemas familiares/económicos afrontados. En cuanto a las principales aportaciones a la formación, destacan el conocimiento de nuevas y diferentes culturas, la estructura cualificada de la que se disfruta en la universidad extranjera y el establecimiento de redes de colaboración científica con profesores y grupos de investigación del exterior.

PALABRAS-CLAVE: Educación superior; Internacionalización; Formación 


\section{INTRODUÇÃO}

A instituição universitária possui na sua concepção inicial um contexto internacional, mediante a presença de professores vindos das mais variadas partes do mundo, objetivando realizar as primeiras atividades de ensino nesses locais (SANTOS, 2001; SEIXAS, 2001). Na década de 80, a internacionalização da educação superior começou a se destacar, principalmente devido a instrumentos como os programas acadêmicos internacionais, e a oferta de ensino a outros países por meio de arranjos interinstitucionais. Destacamos que a globalização age como um catalisador para a internacionalização do ensino superior. Foi o fluxo internacional de pessoas, de informação e de tecnologia que possibilitou ultrapassar fronteiras e conhecer sistemas educacionais ao redor do mundo, trocar experiências e interconectar o conhecimento (KNIGHT, 2004).

O processo de internacionalização dentro do ensino superior pode ocorrer de forma ativa, quando temos políticas para receber os alunos em mobilidade, oferecer serviços educacionais no exterior ou instalar campus em outros países. Ou ainda, de forma passiva, quando não há política clara para envio de alunos para outros locais, nem tampouco recursos materiais e humanos para receber e oferecer tais serviços educativos (LIMA; MARANHÃO, 2009).

Entendemos desta forma tal processo, como indispensável para o desenvolvimento universitário, além disso um potencializador da formação em tal ambiente. Knight (2004, p. 28), define a internacionalização como "o processo que integra uma dimensão global, intercultural e internacional nos objetivos, funções e oferta da educação". Desse modo, a internacionalização seria capaz de contemplar diversos níveis de ação, desde os mais elementares, como a organização de alunos e professores frente as mobilidades, até os mais complexos que envolvem outros organismos como a gestão de programas específicos e parcerias com instituições internacionais (KNIGHT, 2004; WIT, 2002).

Segundo a mesma autora, é importante salientar que o processo de internacionalização é bastante complexo e envolve muitos fatores, como o estabelecimento de acordos de cooperação internacionais, a produção de conhecimento científico, e o fluxo de pessoas entre instituições, por exemplo. Tem como objetivo o atendimento das demandas da sociedade, e de certa forma, também é influenciado pela lógica de competitividade que temos no ensino superior globalizado. Ao aderir a tal processo, as universidades respondem à estas demandas, buscando prestígio e visibilidade, mas também, contribuem para uma formação diferenciada dos sujeitos, e garantem seu desenvolvimento institucional. 
No entanto, para o presente estudo, focamos nosso olhar para a mobilidade estudantil, considerando que este é um dos principais elementos da internacionalização nos dias de hoje. E para Knight (2014), o termo as vezes é confundido com o processo em si, mas ressalta que a mobilidade é apenas parte do todo, e refere-se ao movimento de pessoas, conhecimentos, programas, fornecedores, políticas, ideias, projetos, pesquisas e serviços através das fronteiras.

Muitos estudos têm sido publicados nos últimos anos considerando a internacionalização do ensino superior, entretanto, alguns discutem os conceitos relacionados ao tema (AZEVEDO, 2015; SOUZA et al., 2019; LIMA; MARANHÃO, 2009), descrevem a organização das instituições para atender as demandas do processo, ou os acordos de cooperação firmados (CANAN; SUDBRACK; SILVA, 2020; BASTOS; MANCHOPE; ASSENZA, 2019). Entretanto, ainda são escassos os estudos que se propõe a analisar os programas de mobilidade estudantil como forma de internacionalização (FAGUNDES; LUCE; SILVEIRA, 2019; BRITO; RODRÍGUEZ; MACIEL, 2020) e as contribuições para a formação dos estudantes, sobretudo na área da Saúde, com foco principal na Educação Física.

Para tanto, conduzimos o estudo com acadêmicos dos cursos de Educação Física da Universidade Federal de Pelotas, com o objetivo de analisar as contribuições que a mobilidade estudantil internacional pode proporcionar para a formação inicial, identificando ainda as principais motivações e os desafios encontrados pelos estudantes durante o período no exterior. Destacamos ainda que tal estudo faz parte de uma pesquisa maior que tem o mesmo foco, no entanto ampliando o olhar para diferentes áreas do conhecimento.

\section{CAMINHOS METODOLÓGICOS}

O presente estudo é caracterizado como descritivo, do tipo exploratório com uma abordagem qualitativa das informações. Cabe ressaltar que os dados aqui apresentados fazem parte de uma pesquisa maior que busca compreender quais as contribuições da mobilidade estudantil para a formação de estudantes, considerando diferentes áreas do conhecimento e cursos. Segundo Gil (2011), as pesquisas de cunho descritivo têm como principal objetivo a descrição de características de um determinado fenômeno ou população, e, atrelado a isto, a pesquisa exploratória, busca o mapeamento detalhado deste contexto.

Para tanto foram convidados a participar do estudo, todos os estudantes dos cursos de Licenciatura e Bacharelado em Educação Física da Universidade Federal de Pelotas/RS que saíram para o exterior através de algum programa de mobilidade internacional do ano de 2012 até o ano de 
2019. No total, a partir de informações coletadas junto ao colegiado de curso, foram 19 alunos contemplados, considerando diferentes editais em ambos cursos.

Os estudantes foram contatados via e-mail e redes sociais, e convidados a participar do estudo. Entretanto, do total de possíveis respondentes apenas 16 compuseram a amostra, e responderam o instrumento, após cinco tentativas de contato.

Para a coleta dos dados foi utilizado um formulário online com questões abertas e fechadas, sendo que na primeira parte do instrumento haviam questões sobre os aspectos demográficos (idade, gênero, renda, local de origem, lugar de conclusão do ensino médio, entre outros); e na segunda, questões relacionadas a experiência da mobilidade estudantil (informações sobre o programa contemplado, dificuldades enfrentadas, motivações de escolha, entre outros).

Além disso, os estudantes responderam a uma avaliação relacionada a experiência internacional, em que foram fornecidas algumas afirmativas, e os mesmos deveriam escolher a resposta através de uma escala likert variando em três pontos (1=concordo totalmente; $2=$ não concordo/nem discordo; $3=$ discordo totalmente). Utilizando o estudo de Fagundes, Luce e Silveira (2019) como norteador, optamos por tal forma de coleta dos dados (através de escala) por acreditar ser possível vislumbrar um panorama descritivo da experiência internacional, que foi complementado pelas demais questões do instrumento. As questões abertas buscaram compreender melhor quais as dificuldades de adaptação no país estrangeiro ou no retorno ao Brasil, quais as principais aprendizagens ocorridas no exterior, e os principais aspectos relevantes para a formação dos sujeitos.

Os dados coletados foram agrupados e categorizados de acordo com Bardin (2010) a partir da análise de conteúdo. Na exposição dos mesmos optamos por utilizar valores percentuais e absolutos, e utilizar as falas dos sujeitos no decorrer da discussão dos resultados para complementar os dados descritivos coletados a partir das questões fechadas. O estudo foi submetido e aprovado pelo Comitê de Ética em Pesquisa da Universidade sob o protocolo 4.033.320, e todos os participantes assinaram o Termo de Consentimento Livre e Esclarecido.

\section{RESULTADOS E DISCUSSÃO}

Os dados coletados permitiram compreender um pouco mais da realidade dos estudantes que participaram em programas de mobilidade da Universidade considerando os cursos de Educação Física. O objetivo foi compreender mais sobre a experiência de mobilidade estudantil, e as principais contribuições provenientes deste tempo no exterior. 


\begin{tabular}{lc}
\hline Variável & $\mathbf{N}(\mathbf{\%})$ \\
\hline Sexo & \\
Masculino & $9(56,25 \%)$ \\
Feminino & $7(43,75 \%)$ \\
Renda Familiar* & \\
De 1-2 salários & $4(25 \%)$ \\
De 3-4 salários & $6(37,5 \%)$ \\
5 salários ou mais & $6(37,5 \%)$ \\
Local de origem & \\
Pelotas & $10(62,5 \%)$ \\
Fora da cidade & $6(37,5 \%)$ \\
Lugar de conclusão do Ensino Médio & $14(87,5 \%)$ \\
Escola pública & $2(12,5 \%)$ \\
Escola privada & \\
Curso de língua estrangeira & $8(50 \%)$ \\
Sim & $8(50 \%)$ \\
Não & \\
Curso de formação inicial & $11(68,75 \%)$ \\
Licenciatura & $5(31,25 \%)$ \\
Bacharelado & \\
Bolsista na universidade & $15(93,75 \%)$ \\
Sim & $1(6,25 \%)$ \\
Não & \\
\hline &
\end{tabular}

*Considerando um salário de $\mathrm{R} \$ 998,00$, a partir do Decreto $\mathrm{n}^{\circ} 9.661$, de $1^{\circ}$ de janeiro de 2019. Fonte: Elaborada pelos autores (2021)

Os resultados apresentados na Tabela 1, dizem respeito aos dados demográficos dos participantes da pesquisa. Ressaltamos que as informações são referentes ao período de mobilidade, mas se mantém até hoje. Todos estudantes apresentam formação inicial em Educação Física, sendo que cinco $(31,25 \%)$ do Bacharelado e onze $(68,75 \%)$ da Licenciatura. Com relação ao sexo, nove são homens e sete mulheres, sendo que do total, dez (67,5\%) são de Pelotas e seis $(37,5 \%)$ são de fora da cidade (porém, de regiões próximas). A renda familiar dos participantes varia para cada um deles, no entanto, quatro (25\%) apresentam a renda de 1-2 salários ao mês, seis $(37,5 \%)$ possuem renda de acima de três salários.

Outra questão foi referente ao local de conclusão do ensino médio, sendo que do total de 16 participantes, $14(87,5 \%)$ frequentaram a escola da rede pública e $2(12,5 \%)$ escola da rede privada. Além disso, estes estudantes revelaram uma relação importante com as políticas de permanência no 
Ensino Superior, sendo bolsistas da Universidade. Do total de respondentes, 15 (93,75\%) foram bolsistas na instituição por algum momento, nas modalidades de ensino, pesquisa e/ou extensão.

Tais resultados corroboram com dados extraídos do Exame Nacional de Desempenho dos Estudantes (ENADE) do ano de 2016, disponibilizados pelo Instituto Nacional de Estudos e Pesquisas Educacionais Anísio Teixeira (INEP) que mostra que os concluintes dos cursos de Educação Superior são jovens de até 25 anos, e grande parte ainda vive com os pais. Além disso, mais de $60 \%$ tem renda mensal inferior a três salários mínimos e mais de $60 \%$ cursou o ensino médio em escolas públicas (BRASIL, 2016).

A característica de ter sido bolsista em algum momento da sua formação além de ser uma alternativa de permanência no ensino superior, revela ainda as possibilidades formativas de tal oportunidade, conforme defende Zago (2006) em seu estudo. Para o autor, os acadêmicos que disfrutam das bolsas dentro da universidade, geralmente permanecem mais tempo na instituição, e conseguem se apropriar com uma maior intensidade da cultura acadêmica.

No presente estudo, tal fato é um agente influenciador na escolha por realizar uma mobilidade estudantil internacional, uma vez que os estudantes $(93,75 \%)$ revelaram ter recebido bolsas de pesquisa, extensão e ensino em algum momento da sua graduação. Isso compreende uma aproximação com determinados professores/orientadores, engajamento dentro de laboratórios, participação em eventos, e, ao ter contato com este meio, o desejo de conhecer mais sobre ele pode estar relacionado ao desejo de ir para o exterior. O estudo de Bianchetti et al. (2012) corrobora tal ideia, uma vez que para os autores, ser bolsista propicia aos alunos envolverem-se com orientadores, dominar outras línguas, um alargamento do arcabouço teórico ao ter contato com autores renomados, além de garantir um aprendizado importante ao lidar com a pesquisa, a produção científica, e socialização do conhecimento com pares.

No que diz respeito às oportunidades de realização da mobilidade estudantil internacional, existe um leque amplo de possibilidades considerando o local em que se deseja realizar o intercâmbio, variando de acordo com o tipo de programa e a disponibilidade segundo os editais lançados pelas instituições. No presente estudo, procuramos identificar quais os países em que os alunos realizaram sua mobilidade e as instituições que os receberam, destacando ainda, o programa que estavam vinculados.

Na Figura 1, abaixo, apresentamos os locais de saída de cada estudante que participou do estudo. É possível perceber uma concentração no hemisfério norte, sendo a maioria com uma experiência no continente europeu (Alemanha, Itália e Portugal). Além disso, houveram dois representantes com intercâmbio sendo realizado no continente americano (EUA) e na Oceania (Austrália). 
Figura 1 - Infográfico da mobilidade nos cursos de formação inicial em Educação Física

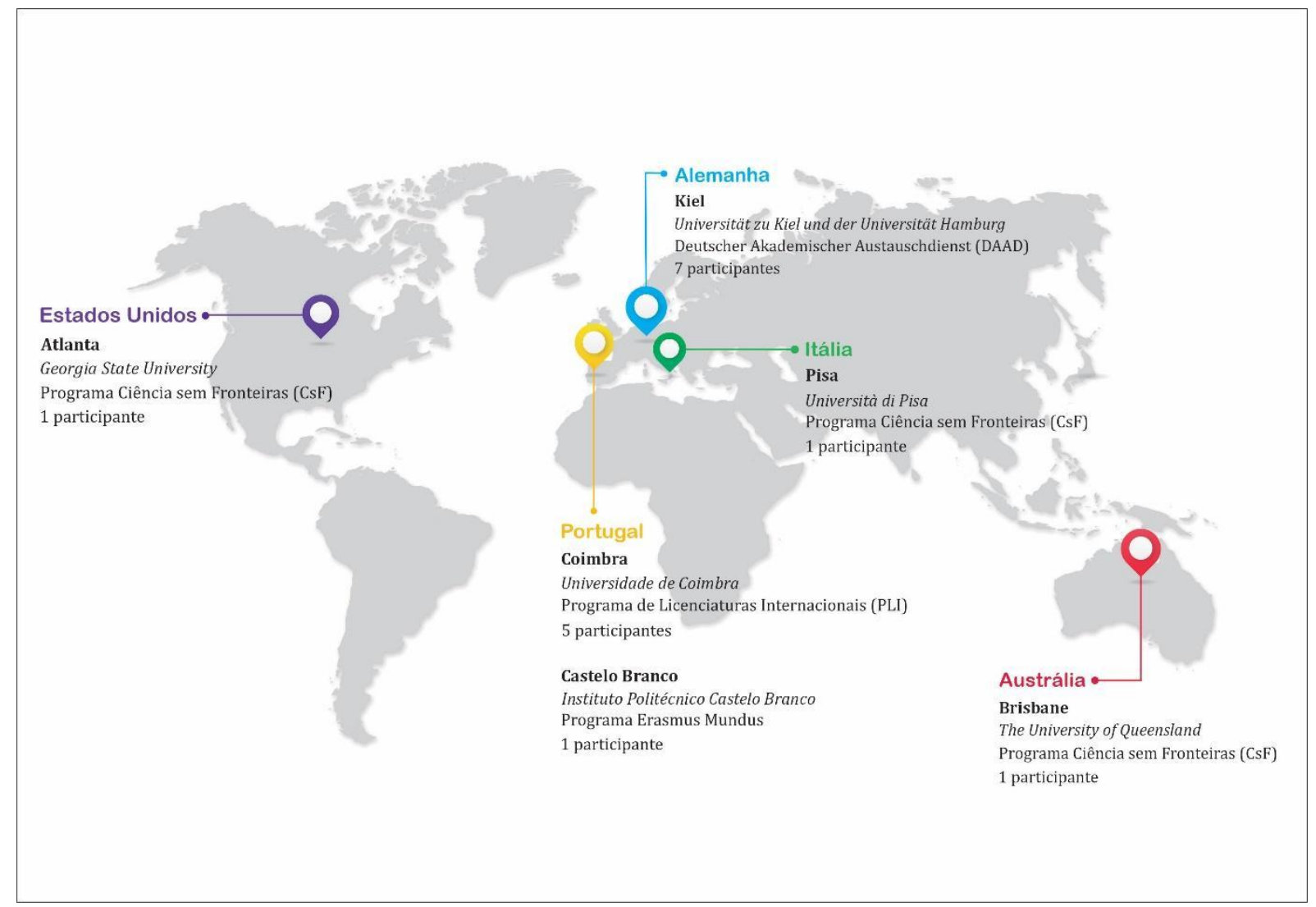

Fonte: Elaborada pelos autores (2021).

Os participantes que foram contemplados com bolsas do Ciência sem Fronteiras residiram nos EUA, Austrália e Itália. O estudante que morou nos EUA, na cidade de Atlanta, esteve vinculado a Georgia State University. O acadêmico que morou na Austrália, fez seu intercâmbio em Brisbane na University of Queensland. Já o participante que fez o intercâmbio na Itália residiu em Pisa, na Università di Pisa.

O programa Ciência sem Fronteiras (CsF) foi implementado no ano de 2011, pelo Ministério da Ciência, Tecnologia e Inovação em parceria com o Ministério da Educação sob a administração da Coordenação de Aperfeiçoamento de Pessoal de Nível Superior (CAPES) e Conselho Nacional de Desenvolvimento Científico e Tecnológico (CNPq).

Tal política de governo visava a formação de recursos humanos no exterior, em instituições de alto nível, com o objetivo de "promover a internacionalização da ciência e tecnologia nacional, estimular pesquisas que gerem inovação, e, consequentemente, aumentar a competitividade das empresas brasileira" (BRASIL, 2016). O mesmo previa a concessão de mais de 100 mil bolsas nos 
seguintes níveis: Graduação, Tecnólogo, Desenvolvimento tecnológico e informação, Mestrado Profissional, Doutorado Sanduíche no exterior, Doutorado Pleno no Exterior e Pós-Doutorado no exterior, em diferentes áreas prioritárias, com destaque para áreas biológicas e engenharias.

Importante ressaltar que o programa não tem editais abertos desde o final de 2014 para a graduação, sendo que na pós-graduação ainda houveram editais esporádicos nos anos de 2015 e 2016. Infelizmente, tal fato se deu em função da avaliação feita pelo MEC no ano de 2016 identificando outras prioridades em sua agenda.

Dos seis participantes que fizeram intercâmbio em Portugal, cinco deles residiram em Coimbra, e vincularam-se à Universidade de Coimbra, através de edital do Programa de Licenciaturas Internacionais (PLI). Tal programa teve sua primeira edição em 2010, com o objetivo de ampliar ações voltadas para a formação inicial do professor para atuar na Educação Básica, elevando de certa forma a qualidade da graduação, melhorando o ensino nos cursos de licenciatura e formação de professores. Além disso, o mesmo prevê uma dupla certificação emitida pela universidade brasileira e a portuguesa (SOUZA; PALAFOX, 2016).

O PLI é um programa institucional, e dessa forma as propostas são feitas pelas instituições de ensino superior brasileiras e contemplam um projeto organizado a partir de um plano de estudos com disciplinas a serem cursadas na universidade estrangeira, sob a supervisão de um tutor no Brasil e outro no exterior. Os alunos contemplados realizam a graduação sanduíche no exterior por um período de dois anos, obtendo ao final a dupla titulação. Os estudantes participantes do presente estudo, obtiveram a graduação de Licenciatura em Ciências do Desporto e fizeram sua formação dentro da Faculdade de Educação Física e Ciências do Desporto na Universidade de Coimbra.

Salientamos ainda que o último edital do PLI sinalizado no site da CAPES foi no ano de 2015, e contemplou neste ano 64 projetos de diferentes instituições (CAPES, 2019)

Um dos outros participantes que realizou sua mobilidade em Portugal, residiu na cidade de Castelo Branco, estando vinculado ao Instituto Politécnico Castelo Branco. Ele foi contemplado com uma bolsa do Programa Erasmus, sendo este a maior iniciativa de intercâmbio estudantil do mundo e uma das mais antigas. Tal iniciativa faz parte do Programa Sócrates, implementado em 1987, desenvolvido pela união europeia, que visa a cooperação na área da educação em diferentes setores (CRUZ, 2011).

Através do Erasmus, as universidades da Europa organizam a mobilidade de estudantes, através da cooperação entre instituições, e os estudantes efetuam períodos de estudos em diferentes localidades. Como objetivo principal do programa, está a promoção de intercâmbio cultural e linguístico, o que culmina por propiciar um grande enriquecimento pessoal, acadêmico e profissional, a partir do que é experenciado pelos participantes. 
Houveram diferentes configurações do programa e atualmente o mesmo recebe o nome Erasmus+, uma vez que além da mobilidade individual com ênfase na aprendizagem, ainda prevê estágios a serem realizados nas instituições europeias, focando no desenvolvimento profissional e formação de pessoal em diferentes setores da educação (VIEIRA, 2015).

Os sete estudantes que fizeram intercâmbio na Alemanha, residiram na cidade de Kiel, e estiveram vinculados com a Universidade Christian Albrechts de Kiel/Universidade de Hamburgo (Universität zu Kiel und der Universität Hamburg). O programa que fizeram parte foi o DAAD (Deutscher Akademischer Austauschdienst), um serviço de intercâmbio alemão. Tal iniciativa, é uma organização de fomento ao intercâmbio, sem fins lucrativos, que conta com 241 instituições cadastradas e oferta cerca de aproximadamente 100 mil bolsas por ano. A iniciativa em ir para a Alemanha faz parte de uma ação interinstitucional de parceria com a Universidade Federal da Paraíba, como parte do projeto de extensão "Educação, Sociedade e Esportes: integração cultural Brasil-Alemanha-Dinamarca", que visa oportunizar uma aproximação social, de costumes e tradições entre os países, facilitando a melhor compreensão da sociedade e educação (UFPB, 2020). A ideia é que ocorra a mobilidade acadêmica internacional, em diferentes níveis formativos (graduação, mestrado e doutorado) e que tais possibilidades possa contribuir para a formação dos participantes.

Os dados apresentados na Tabela 2, abaixo, são referentes à mobilidade estudantil, buscando compreender um pouco mais sobre os motivos que levaram os participantes a realizar um intercâmbio, quais os fatores que interferiram na escolha da Universidade, por quem foram auxiliados antes de sua saída para o exterior, quais as dificuldades de organização enfrentadas, onde ficaram durante o período de mobilidade, e ainda, quais as contribuições que tiveram para sua formação a partir da experiência internacional.

Tabela 2 - Aspectos relacionados à mobilidade estudantil

\begin{tabular}{lc}
\hline Aspecto & $\mathbf{N}(\mathbf{\%})$ \\
\hline Programa que foi contemplado & \\
Programa DAAD & $7(43,75 \%)$ \\
Programa de Licenciaturas Internacionais & $5(31,25 \%)$ \\
Programa Ciência sem Fronteiras & $3(18,75 \%)$ \\
Programa Erasmus & $1(6,25 \%)$ \\
O que motivou a fazer a mobilidade? ${ }^{*}$ & \\
Incentivo dos professores & $8(50 \%)$ \\
Necessidade de qualificação profissional & $9(56,25 \%)$ \\
Vontade própria & $11(68,75 \%)$ \\
Melhoria financeira & $1(6,25 \%)$
\end{tabular}


Incentivo de pais e amigos

Escolha da Universidade estrangeira *

Recomendação de professores

Disponibilidade conforme edital

$13(81,25 \%)$

Facilidade da língua falada

$2(12,5 \%)$

Outro (especificar outro)

$1(6,25 \%)$

Quem auxiliou na saída

Professores e colegiado de curso

$11(68,75 \%)$

Família e amigos

$4(25 \%)$

Ninguém ajudou

$2(12,5 \%)$

Dificuldades na organização *

Atendimento do edital e/ou problemas familiares/financeiros

$14(62,5 \%)$

Dificuldades com a língua estrangeira

$2(12,5 \%)$

Organização da grade curricular

$3(18,75 \%)$

Sem dificuldade

$1(6,25 \%)$

Onde ficou durante a mobilidade?

Fora da Universidade

$15(93,75 \%)$

Dentro da Universidade

$1(6,25 \%)$

Contribuições para a formação *

Oportunidade de conhecer uma cultura e pessoas diferentes

$16(100 \%)$

Estar em uma infraestrutura mais qualificada

$16(100 \%)$

Estabelecer redes de colaboração

$10(62,5 \%)$

Aprendizagem de outro idioma

$5(31,25 \%)$

Desenvolvimento da autonomia

$8(50 \%)$

*Os alunos poderiam assinalar mais de um item nestas questões.

Fonte: Elaborada pelos autores (2021).

Com relação aos motivos de saída, a maioria dos sujeitos $(\mathrm{n}=11 ; 68,75 \%)$ revelou uma vontade individual em realizar a mobilidade no exterior, a necessidade de qualificação profissional $(\mathrm{n}=9 ; 56,25 \%)$ ou incentivo dos professores $(\mathrm{n}=8 ; 50 \%)$. Tais resultados são semelhantes aos encontrados por Berghoff, Taboadela e Brandenburg (2014) em seu estudo, que analisou os impactos do programa Erasmus em estudantes. Entre as principais motivações para estudar no exterior estavam: a oportunidade de morar no exterior e conhecer pessoas novas, melhorar a proficiência em uma língua estrangeira, desenvolver a autonomia, a capacidade de se adaptar a situações diversas, ter maior proatividade, e, melhorar as perspectivas de carreira no futuro.

Sobre o aspecto individual, Oliveira e Freitas (2016), ao realizarem um estudo com estudantes brasileiros, estrangeiros e professores, mostraram que o amadurecimento e a conquista pela autonomia pessoal foram os principais motivos que levaram os participantes a realizarem uma mobilidade acadêmica internacional.

Já a escolha da Universidade segundo os participantes, aconteceu principalmente por disponibilidade conforme o edital $(n=13 ; 81,25 \%)$ ou por recomendação de professores $(n=6$; 
37,5\%). Sobre esta questão, Duarte et al. (2012) mencionam que a possibilidade de estudar em uma universidade que tenha reconhecimento e prestígio internacional, tem o potencial de contribuir para o desenvolvimento profisssional dos sujeitos, representando uma motivação para a realização de um intercâmbio. Além disso, para os autores, a possibilidade de produção acadêmica conjunta, é um exemplo que efetiva esta ideia, uma vez que ao estar em uma instituição junto com professores e estudantes da mesma área de formação, desfrutando muitas vezes de laboratórios e unidades de pesquisa avançados, a produção científica representa uma importante contribuição para os acadêmicos que realizam a mobilidade.

Avançando na ideia, Lauermann (2012), defende que existem razões acadêmicas para alguém fazer a mobilidade estudantil e escolher o país de destino. Ele denomina de "fatores de atração e repulsão", sendo os primeiros, as condições desejadas associadas aos países que se deseja ir (educação de qualidade, custos, reputação do país, entre outros), e os segundos as condições que fazem com que alunos rejeitem seu país de origem (poucas oportunidades educacionais, condição socioeconômica insatisfatória, entre outros). Segundo o autor, tais mecanismos são elementos que regulam de certa forma a mobilidade.

No presente estudo tais razões poderiam ser relacionadas aos motivos que levaram os acadêmicos a realizarem a mobilidade estudantil e os fatores que contribuíram para a escolha da universidade. Entre os "fatores de atração", destacamos a necessidade de qualificação profissional em uma instituição renomada, a possiblidade de melhoria financeira a partir do seu desenvolvimento acadêmico/profissional, a vontade de conhecer um país diferente, o incentivo oriundo de pais, amigos e também professores. Além disso, a disponibilidade de acordo com os editais e a facilidade da língua falada no país de destino, também podem ser considerados como "fatores de atração". Considerando os "fatores de repulsão", ou seja, os motivos que levariam os acadêmicos deixarem o seu país e Universidade, não foi possível identificá-los de maneira pontual a partir dos dados coletados. A partir da leitura dos dados, foi possível destacar principalmente razões que levam estes alunos procurar determinado lugar, do que as razões para não ficar em sua universidade ou país. Além disso, tais resultados têm relação com a sua motivação, apresentada anteriormente, com as oportunidades ofertadas e as condições de vida dos sujeitos.

Com relação às principais dificuldades encontradas na organização da saída, a principal delas foi atender as demandas do edital e/ou problemas familiares/financeiros $(n=14 ; 62,5 \%)$, sendo que apenas um deles $(n=1 ; 6,25 \%)$ não relatou problema. Este aspecto foi agrupado desta forma pois apenas um sujeito relatou problemas pessoais na família, e os demais, tiveram como principal problema a confecção de passaporte e documentação necessária para realizar a viagem para o exterior. Além da escolha, os professores também foram as pessoas que mais auxiliaram na saída 
para o exterior segundo 11 participantes $(n=11 ; 68,75 \%)$, e em segundo lugar a família ou amigos $(\mathrm{n}=4 ; 25 \%)$.

Talvez as dificuldades encontradas pelos acadêmicos possam ser explicadas pelo perfil dos mesmos, oriundos de escolas públicas e com uma renda financeira média. Este fato corrobora com o perfil dos sujeitos que estão inseridos no ensino superior (BRASIL, 2016) e muitos programas, como o Ciência sem Fronteiras, por exemplo, são desenvolvidos também pra contemplar tal público. O suporte recebido pelos professores reflete a preocupação que os mesmos têm com a formação, como já mencionado.

Neste sentido, Nogueira, Aguiar e Ramos (2008), enfatizam que, a valorização da dimensão internacional na formação dos filhos é um elemento que tem emergido no conjunto das práticas educativas de famílias de classe média brasileira, principalmente nas mais elevadas e tal fato também se deve as políticas que são desenvolvidas voltadas para este setor.

Tais dificuldades representam de certa forma barreiras para adesão a um programa de mobilidade estudantil. O estudo de Fagundes, Luce e Silveira (2019), realizado com participantes do Ciências sem Fronteiras, revelou que além dos percalços mencionados ainda podemos citar o tempo demandado para a conclusão do curso, em função da dificuldade de aproveitamento dos créditos cursados em um país estrangeiro.

Sobre o local onde ficar no exterior a maioria dos alunos ficou residindo em ambientes fora da universidade $(n=15 ; 93,75 \%)$ em apartamentos alugados ou hotéis, e apenas um $(n=1 ; 6,25 \%)$ morou no campus da universidade, uma vez que. das universidades frequentadas pelos sujeitos da pesquisa somente uma ofertava tal serviço.

Informações referentes aos programas de mobilidade foram coletadas junto aos sujeitos, com relação ao tipo de edital contemplado, o ano de saída para o exterior, a quantidade de tempo em uma Universidade estrangeira e como ficou sabendo do programa. Podemos perceber que do total de 16 participantes a maioria deles foi contemplado por edital do DAAD ( $n=7 ; 37,5 \%)$ e saiu para o exterior em 2018. Outros cinco sujeitos $(n=5 ; 31,25 \%)$ foram participantes do Programa de Licenciatura Internacionais e foram para o exterior em 2012. Houveram ainda três estudantes contemplados pelo Ciência sem Fronteiras $(n=3 ; 18,75 \%)$ e saíram para as universidades estrangeiras em 2013 e 2014. Além disso, houve mais um estudante, contemplado pelo Erasmus $(\mathrm{n}=1 ; 6,25 \%)$ e foi para o exterior em 2017.

A quantidade de tempo no exterior também foi variável de acordo com os editais em que os alunos foram contemplados. A maioria ficou no exterior um período de até um mês $(n=7 ; 43,75)$ ou um período superior a um ano $(n=6 ; 37,50)$. Sendo que houveram ainda três estudantes que ficaram no exterior um período de dois meses a um ano $(\mathrm{n}=3 ; 18,75)$. 
No caso do Ciência sem Fronteiras o tempo não ultrapassa 12 meses (graduação sanduíche), sendo que o estudante não pode estar no primeiro ano de curso (BRASIL, 2016). A normativa para o PLI prevê um período de dois anos de estudo no exterior (pois trata-se de uma dupla titulação), sendo que o último ano de graduação deve ser cursado na instituição de origem (BRASIL, 2020). Quanto ao Erasmus o mesmo sofre variação do período de duração de acordo com edital, sendo que as bolsas variam de dois a 24 meses (ERASMUS, 2020). Já com relação ao DAAD, não existe uma restrição do tempo a ser cursado no exterior, e ele varia de acordo com a proposta institucional organizada (DAAD, 2020).

Sobre a forma que ficou sabendo do edital, a maioria dos estudantes relatou ter recebido informações do colegiado e dos professores dos cursos $(n=9 ; 56,25)$. Outros quatro $(n=4 ; 25,00 \%)$ mencionaram ter ficado sabendo por colegas e amigos, e ainda dois $(n=2 ; 12,5 \%)$ deles mencionaram ter recebido informações na Universidade e outro $(n=1 ; 6,25 \%)$ através da mídia. Cabe ressaltar que existe um setor responsável pela divulgação e organização das experiências de mobilidade estudantil dentro da instituição, e dessa forma os alunos conseguem ter acesso aos editais, e ter acompanhamento em um país estrangeiro.

Outro aspecto importante investigado diz respeito aos elementos que os participantes julgaram importantes para sua formação após a realização do intercâmbio. A totalidade de sujeitos mencionou que as principais contribuições para sua formação são a oportunidade de conhecer uma cultura e pessoas diferentes, ou estar em uma infraestrutura mais qualificada. Além disso, estabelecer redes de colaboração com professores e acadêmicos estrangeiros também foi considerada como uma contribuição importante $(n=10 ; 62,5 \%)$.

Sobre este assunto, Canuto (2014) defende que a vivência no exterior é importante o preparo para aprender com as diferenças, além de aceitar críticas e novos desafios. E no contexto da formação, Fagundes, Luce e Silveira (2019) complementam a ideia, mencionando que o ensino em uma Universidade na Europa é diferente do oferecido no Brasil, em que as exigências são outras, e se espera independência por parte dos alunos, que este consiga resolver seus problemas e conflitos, e ainda amplie as competências de forma autônoma.

Os estudantes complementaram suas respostas a partir das questões abertas contidas no instrumento de pesquisa, conforme abaixo:

Foram muitas aprendizagens, mas a principal foi que os alunos lá são extremamente disciplinados. Não existe celulares e todos os alunos participam das práticas. Sobre os professores, sinceramente, são tão competentes quantos os meus foram, o que eles têm a mais é infraestrutura. Fiquei impactada com tudo que a faculdade de EF tem na Alemanha (Sujeito 2). 
Aprender outro idioma, as avaliações lá eram orais e um estágio que fiz em um clube de futebol. Me ajudou bastante a aprender e conhecer melhor o dia a dia, como trabalha um clube, uma escolinha de futebol, mas entrar na cultura e formação deles (Sujeito 7).

Talvez uma das principais contribuições da experiência internacional possa ser exemplificada quando analisamos um dado relacionado à formação continuada dos sujeitos. Foi possível identificar que os participantes seguiram sua formação em nível de Pós-Graduação sendo que de todos eles seis $(n=6 ; 37,5 \%)$ possuem mestrado, cinco $(n=5 ; 31,25 \%)$ especialização e dois $(n=2 ; 12,5 \%)$ doutorado, sendo estas formações em andamento ou concluídas.

No que tange as oportunidades de retorno do que foi experenciado à Universidade, todos os estudantes comentaram que só foi possível uma conversa informal com professores e colegas. Entretanto, dez deles $(n=10 ; 62,5 \%)$ conseguiram participar de eventos institucionais ou locais e quatro $(n=4 ; 25 \%)$ deram o retorno apenas com a entrega de relatórios sobre a experiência. Tal resultado corrobora com o estudo de Cunha e Raschke (2019), em que os acadêmicos participantes do CsF entrevistados revelaram que o retorno para a Universidade foi feito apenas em conversas informais com colegas ou entrega de relatórios para as agências de fomento.

Aquele sujeito que atravessa um tempo de mobilidade acadêmica, pode acabar atribuindo um valor e um significado diferente ao lugar em que vive, sendo que o "estar em casa" pode não ser mais limitado ao seu endereço, uma vez que pensa o espaço de uma forma móvel e global (MURPHY-LEJEUNE, 2002). Nesse sentido, se torna importante oportunizar uma forma de contribuição com os demais colegas que não usufruem de tal experiências, para que os benefícios possam potencializar ainda mais a formação inicial na universidade.

A Tabela 3, traz os resultados referentes a uma avaliação reflexiva da experiência pelos estudantes, considerando os elementos relacionados ao ambiente durante o período de mobilidade. Para tanto responderam a questões fechadas através de uma escala, onde para cada indicador/afirmativa que havia no instrumento, eles deveriam utilizar as opções: concordo totalmente, nem concordo nem discordo, discordo totalmente.

Tabela 3 - Avaliação dos indicadores relacionados ao ambiente em que foi realizada a mobilidade

\begin{tabular}{lccc}
\hline Indicador & $\begin{array}{c}\text { Discordo } \\
\text { Totalmente }\end{array}$ & $\begin{array}{c}\text { Nem } \\
\text { concordo nem } \\
\text { discordo }\end{array}$ & $\begin{array}{c}\text { Concordo } \\
\text { Totalmente }\end{array}$ \\
\hline \multicolumn{4}{c}{ Elementos relacionados ao ambiente durante o período de mobilidade } \\
\hline $\begin{array}{l}\text { 1. Haviam pessoas responsáveis na Universidade } \\
\text { para dar informações básicas. }\end{array}$ & $1(6,25 \%)$ & $2(12,5 \%)$ & $13(81,25 \%)$ \\
$\begin{array}{l}\text { 2. Me senti completamente acolhido por toda } \\
\text { comunidade universitária. }\end{array}$ & $1(6,25 \%)$ & $1(6,25 \%)$ & $14(87,5 \%)$
\end{tabular}


3. Os colegas eram solícitos e colaboravam mostrando a estrutura da Universidade e também pontos turísticos/recomendações sobre o local.

4. Os professores me trataram como um nativo do lugar.

5. Tive grandes possibilidades de intercâmbio cultural com colegas nativos da Universidade estrangeira.

6. Tive grandes possibilidades de conhecer outros países e culturas enquanto realizei a mobilidade.

7. Os colegas me discriminavam enquanto estrangeiro.
$2(12,5 \%)$
$4(25 \%)$
$10(62,5 \%)$
$5(31,25 \%) \quad 5(31,25 \%) \quad 6(37,5 \%)$
$3(18,75 \%) \quad 2(12,5 \%) \quad 11(68,75 \%)$

$3(18,75 \%)$

$13(81,25 \%)$

$13(81,25 \%) \quad 1(6,25 \%) \quad 2(12,5 \%)$

$9(56,25 \%) \quad 6(37,5 \%) \quad 1(6,25 \%)$

$10(62,5 \%) \quad 2(12,5 \%) \quad 4(25 \%)$

8. Tive dificuldades com a língua estrangeira no país em que estava realizando a mobilidade.

9. Consegui juntar dinheiro durante o período de mobilidade pela bolsa ser maior do que meus gastos.

Fonte: Elaborada pelos autores (2021).

Com relação aos elementos relacionados ao período de intercâmbio, a maioria dos estudantes concordou com a afirmativa de que "Haviam pessoas responsáveis na Universidade para dar informações básicas" ( $\mathrm{n}=13 ; 81,25 \%)$, oportunizando a acolhida na instituição. Além disso, se sentiram completamente acolhidos pela comunidade universitária ( $\mathrm{n}=14 ; 87,50 \%)$, e "Os colegas eram solícitos e colaboravam mostrando a estrutura da Universidade e também pontos turísticos/recomendações sobre o local $(n=10 ; 62,5 \%)$.

Destacamos que a estadia em um país estrangeiro pode trazer um processo contínuo de estresse, principalmente em função da perda de elementos de proteção psíquica como a cultura de origem, a rede de apoio social (família e amigos), o status que o estudante tinha antes de sair, e dificuldade de expressão sem a língua materna, entre outros (MARTINS-BORGES, 2013). Entretanto, os participantes do presente estudo não demonstraram ter sofrido com tal tipo de problema.

Segundo os estudantes a troca de experiências com outros colegas da instituição e de outros países que visitaram contribuíram para que a experiência fosse ainda melhor, uma vez que a maioria relatou ter tido grandes possibilidades de conhecer outros países e culturas enquanto realizou a mobilidade $(\mathrm{n}=11 ; 68,75 \%)$, e também de realizar intercâmbio cultural com colegas nativos da Universidade estrangeira $(\mathrm{n}=13 ; 81,25 \%)$.

Tal fato também pode ser percebido inclusive pelas questões abertas em que os mesmos sinalizam as contribuições que estas oportunidades proporcionaram para seu desenvolvimento. 
No período em que passei na Alemanha (por mais breve que seja) só tenho elogios referente a educação de todos, isso se reflete em tudo, exemplo das vias públicas, restaurantes. Além disso, qualquer tipo de ocupação é valorizada. Na Universidade, faltam palavras para descrever a infraestrutura e as politicas de incentivo ao estudante (Sujeito 3).

Alguns aspectos negativos que podem ter ocorrido durante o período de mobilidade foram levantados pelo instrumento. A maioria dos estudantes $(n=13 ; 81,25 \%)$ discordou da afirmativa "Os colegas me discriminavam enquanto estrangeiro", revelando que apesar de estar em um local diferente não sofreram qualquer tipo de diferenciação por parte dos nativos do lugar. Além disso, discordaram da afirmativa relacionada às dificuldades com a língua estrangeira $(n=9 ; 56,25 \%)$, revelando que isto não foi um problema durante o intercâmbio.

Sobre a dificuldade de adaptação em um local estrangeiro e a discriminação, alguns estudos (ALENCAR-RODRIGUES; STREY, 2010; OLIVENCIA, 2014), sinalizam que, quanto maior a diferença de cultura, maior será a dificuldade de adaptação no ambiente, representando um problema realização de um intercâmbio. Dessa forma, os estrangeiros encontram uns nos outros o apoio que necessitam para seguir adiante durante o seu período de imigrante em um país estrangeiro. Em casos mais extremos, a discriminação racial e social contra estudantes internacionais foi presente como um fator de risco para a saúde mental destes sujeitos (CARRILLO, 2016).

Outro aspecto levantado diz respeito aos aspectos financeiros, onde os participantes discordaram da afirmativa "Consegui juntar dinheiro durante o período de mobilidade pela bolsa ser maior do que meus gastos $(n=10 ; 62,50 \%)$ " indicando que mesmo recebendo uma bolsa de estudos considerável, não foi suficiente para conseguirem juntar dinheiro.

No que diz respeito aos indicadores relacionados ao currículo e formação, apresentados na Tabela 4, os estudantes foram questionados sobre a instituição em que estavam, a estrutura do currículo e corpo docente, além das estratégias pedagógicas e envolvimento com grupos de pesquisa.

Tabela 4 - Avaliação dos indicadores relacionados ao currículo e a formação em nível internacional

\begin{tabular}{lccc}
\hline Indicador & $\begin{array}{c}\text { Discordo } \\
\text { Totalmente }\end{array}$ & $\begin{array}{c}\text { Nem } \\
\text { concordo nem } \\
\text { discordo }\end{array}$ & $\begin{array}{c}\text { Concordo } \\
\text { Totalmente }\end{array}$ \\
\hline \multicolumn{4}{c}{ Indicadores relacionados ao currículo e formação } \\
\hline $\begin{array}{l}\text { 1. Tive a oportunidade de cursar todas as disciplinas } \\
\text { que me interessei. }\end{array}$ & $2(12,5 \%)$ & $2(12,5 \%)$ & $12(75 \%)$ \\
$\begin{array}{l}\text { 2. A estrutura curricular e o corpo docente eram } \\
\text { superiores aos da minha universidade no Brasil. }\end{array}$ & $3(18,75 \%)$ & $5(31,25 \%)$ & $8(50 \%)$
\end{tabular}


3. Considero que meu aproveitamento nas disciplinas foi satisfatório.

4. A Universidade tinha uma boa estrutura física.

$2(12,5 \%) \quad 1(6,25 \%)$

$1(6,25 \%)$

$9(56,25 \%) \quad 6(37,5 \%)$

$10(62,5 \%) \quad 2(12,5 \%)$
13

15

$(93,75 \%)$

$1(6,25 \%)$

$4(25 \%)$ durante a mobilidade.

Fonte: Elaborada pelos autores (2021).

Com relação as disciplinas cursadas, a maioria dos sujeitos concorda que teve a oportunidade de cursar todas aquelas que se interessaram $(n=12 ; 75 \%)$ e que seu aproveitamento foi satisfatório ( $\mathrm{n}=13 ; 81,25 \%)$. Além disso, concordaram que a estrutura curricular e o corpo docente da Universidade estrangeira eram superiores aos da Universidade aqui do Brasil ( $\mathrm{n}=8 ; 50 \%)$ e que a instituição tinha uma boa estrutura física $(n=15 ; 93,75 \%)$.

Sobre estes aspectos o estudo de Cunha e Raschke (2019) corrobora com os dados apresentados, uma vez que os acadêmicos participantes ficaram satisfeitos com a estrutura da universidade e disponibilidade de horários para exploração dos laboratórios de estudo. Além disso, no processo de aprendizado puderam contar com a presença de monitores (estudantes de mestrado e doutorado) no suporte aos docentes, facilitando a compreensão dos conteúdos.

A maioria dos estudantes discordou que as estratégias pedagógicas e de ensino utilizadas na Universidade estrangeira eram melhores do que as utilizadas aqui no Brasil ( $\mathrm{n}=9 ; 56,25 \%$ ), revelando que o a formação inicial fornecida aqui contempla suas necessidades. Outro aspecto relevante diz respeito a oportunidade de envolvimento em grupos de pesquisa, publicação de artigos ou participação em projetos durante a mobilidade. Grande parte dos participantes $(n=10 ; 62,5 \%)$ discordou da afirmativa de que tiveram tal oportunidade.

Em estudo realizado por Masetto (2003), não houve a necessidade de adaptação ao modelo de ensino nas universidades estrangeiras, uma vez que os participantes da pesquisa se sentiram familiarizados com aulas expositivas e/ou aulas expositivas dialogadas, uma vez que representam os recursos didáticos mais recorrentemente explorados no ambiente educacional brasileiro.

Ainda sobre os aspectos pedagógicos, o estudo de Junior e Matos (2017), objetivou relatar as experiências de discentes do curso de Odontologia da UFMG, no Programa Ciência sem Fronteiras, e revelou que nas aulas há uma abordagem mais prática com a participação ativa dos alunos em plataformas digitais, e um número menor de aulas presenciais foi mencionado pelos entrevistados, revelando que a peça principal na aprendizagem é o aluno.

Segundo Guazzelli et al. (2015) as universidades estrangeiras são grandes centros de pesquisa, e podem colaborar para a criação de redes de interação e influenciar na capacidade de 
produção dos sujeitos que as vivenciam. Avançando nesta ideia Lima e Maranhão (2009) defendem que, os países reconhecidos pela capacidade de atração de estudantes, além de conseguir captar recursos financeiros diretos e indiretos mediante programas e acordos institucionais, têm ainda outras vantagens como: a contribuição na ampliação da rede mundial de influência cultural e política, se beneficiar com mão de obra especializada, criar ambientes de aprendizagem multicultural, entre outros.

Cabe ressaltar que para o processo de internacionalização acontecer, é necessária uma organização da instituição para atender as demandas dos acordos firmados e editais lançados a nível nacional e internacional. Destacamos que no ano de 2012, existe a criação da CRInter (Coordenadoria de Relações Internacionais), dentro da Universidade Federal de Pelotas, para que sejam organizados os acordos de cooperação internacional, bem como o fluxo de saída de professores e alunos, e outros aspectos relacionados à internacionalização (RIBEIRO et al. 2016).

Ficou evidenciado o apoio que os sujeitos tiveram de tal órgão a partir dos seus relatos nas questões abertas, e talvez, só tenham conseguido usufruir mais da experiência pelo fato deste apoio positivo da instituição.

O que parece ficar evidenciado é a alta capacidade de atendimento das demandas de aprendizagem dos acadêmicos, e a qualidade do ensino e infraestrutura usufruídos. Aliado a isso, a conquista da autonomia, fazendo com que os alunos sejam o centro do processo de aprendizagem, pode ser uma importante contribuição para a formação não somente acadêmica, mas profissional dos sujeitos, acarretada pela participação em um programa de mobilidade estudantil. Tais aspectos também foram levantados nas questões abertas direcionadas aos alunos, conforme abaixo:

Lá a infraestrutura era maravilhosa e os laboratórios muito bem aparelhados, porém, os alunos de graduação usufruíam muito pouco disto, pois começavam o trabalho com pesquisa apenas na pós-graduação, enquanto nós aqui temos a oportunidade de começar bem cedo, e acabamos por produzir bem mais que eles, mesmo sem uma estrutura adequada (Sujeito 3).

Diversidade cultural, disciplinas e professores muito conceituados, linguagem habitual portuguesa e também nas línguas inglesas e espanhola devido ao número acentuado de estudantes de outros países na mesma turma e até mesmo aulas e conteúdos literários em outras línguas (Sujeito 6).

Em estudo de Berghoff, Taboadela e Brandenburg (2014), fica evidenciado que os estudantes que vivenciam programas de internacionalização sobretudo de mobilidade, desenvolvem competências transversais e há um aumento de percentuais de empregabilidade sobretudo no hemisfério norte. 
Considerando os dados, identificamos os ganhos que os acadêmicos tiveram com a participação dentro dos programas, uma vez que vivenciaram esta experiência internacional, adquiriram conhecimento, compartilharam saberes e estiveram em universidades renomadas. Muitos estudantes conseguiram se desenvolver profissionalmente e avançar seus estudos a nível de formação continuada, engajando-se na pós-graduação. Do total de participantes, nove realizam sua formação continuada em nível de mestrado ou doutorado e têm interesse de prosseguir na carreira acadêmica, e mencionaram que a partir de sua estadia no exterior e contato com docentes, foram incentivados para tal. Nesse sentido, as competências que desenvolveram serviram de subsídio para que seu currículo fosse melhorado e seu interesse pela pesquisa e pelo aprendizado fosse ampliado.

Sobre esse aspecto, podemos perceber que os ganhos maiores ficaram por conta do currículo formal (LEASK, 2015), sobretudo para os estudantes que vivenciaram a experiência internacional. No que diz respeito ao currículo informal, como os serviços de apoio, atividades adicionais, ficaram em segundo plano no retorno para a instituição de origem destes sujeitos, sobretudo pela dificuldade em se compartilhar tais experiências em momentos sistematizados e institucionalizados e transformá-las em estratégia pedagógica na formação inicial.

\section{CONSIDERAÇÕES FINAIS}

O presente estudo objetivou analisar as contribuições que a mobilidade estudantil internacional pode proporcionar para a formação inicial, identificando ainda as principais motivações e os desafios encontrados pelos estudantes durante o período no exterior. Quanto ao perfil dos estudantes, foi possível averiguar que a maioria dos sujeitos é oriundo da cidade de Pelotas, frequentaram a escola pública durante a Educação Básica, e são de classe média.

Ficou evidenciada uma busca por mobilidade no hemisfério norte com destaque para o continente europeu e uma avaliação positiva da experiência internacional pelos estudantes. Como principais motivos para a realização do intercâmbio, podemos citar a vontade de vivenciar uma cultura diferente e a busca por qualificação profissional. As principais contribuições estão relacionadas ao fato dos participantes conseguirem usufruir de uma infraestrutura qualificada, conhecer um ambiente intercultural, e ainda potencializar o estabelecimento de redes de colaboração científica, reverberando na sua formação acadêmica e profissional. Tal fato tem reflexo na continuidade dos seus estudos a nível de pós-graduação e vontade de continuar avançando em suas carreiras. 
Grande parte dos estudantes entrevistados foram bolsistas na sua formação inicial, e tal fato pareceu influenciar na sua escolha por realizar a mobilidade e ir para determinadas instituições. Durante o processo, conseguiram sentir-se acolhidos na universidade estrangeira, tiveram oportunidades de um intercâmbio cultural ao interagir com outros colegas, e também conhecer outros países.

Apesar da experiência significar uma qualificação na formação dos sujeitos, tal aspecto parece ser mais individual do que coletivo, uma vez que não houveram muitas oportunidades de compartilhamento das mesmas na formação inicial. Mesmo se tratando de um estudo localizado, e os resultados serem mais aplicados para a realidade da instituição estudada, conhecer este contexto possibilita a realização de novas investigações. Destacamos a necessidade de realizar estudos futuros que consigam captar aspectos mais pontuais referentes a formação inicial em Educação Física, podendo abordar questões como o ensino dos esportes, a relação com a área da saúde, ou até mesmo a formação de professores.

Cabe ressaltar ainda que apesar de haverem ainda possibilidades de usufruir da mobilidade acadêmica internacional, alguns programas como o Ciência sem Fronteiras e Programa de Licenciaturas Internacionais foram descontinuados em âmbito nacional, considerando o ensino de graduação. Tal fato, revela um retrocesso não somente para a área de Educação Física, mas para todas as demais, uma vez que menos alunos poderão ter acesso a uma experiência multicultural, impactando na sua formação.

\section{REFERÊNCIAS}

ALENCAR-RODRIGUES, Roberta de; STREY, Marlene Neves. Orquestrando vozes de gênero de estudantes estrangeiros/as latino-americanos/as. Psico, Porto Alegre, v. 41, n. 1, p. 47-56, jan./mar. 2010. Disponível em: https://revistaseletronicas.pucrs.br/ojs/index.php/revistapsico/article/view/3755/5216. Acesso em: 14 mai. 2020.

AZEVEDO, Mario Luiz Neves de. Internacionalização ou transnacionalização da educação superior: entre a formação de um campo social global e um mercado de ensino mundializado. Crítica Educativa, Sorocaba, v. 1, n. 1, p. 56-79, já./jun. 2015. Disponível em: https://www.criticaeducativa.ufscar.br/index.php/criticaeducativa/article/view/24/171. Acesso em: 14 maio 2020.

BARDIN, Laurence. Análise de conteúdo. 4. ed. Lisboa: Edições 70, 2010.

BARTELL, Marvin. Internationalization of universities: a university culture-based framework. Higher Education, Winnipeg, v. 45, n. 1, p. 43-70, 2003. Springer Science and Business Media LLC.

BASTOS, Carmen Celia Barradas Correia; MANCHOPE, Elenita Conegero Pastor; ASSENZA, Marta Lucia Alves. A internacionalização da educação superior na Universidade Estadual do Oeste do Paraná -

UNIOESTE. Revista Internacional de Educação Superior, Campinas, v. 5, p. 1-22, 2019. Disponível em: 
https://periodicos.sbu.unicamp.br/ojs/index.php/riesup/article/view/8653899/19176. Acesso em: 14 mai. 2020.

BIANCHETTI, Lucídio et al. A iniciação à pesquisa no Brasil: políticas de formação de jovens pesquisadores. Educação, Santa Maria, v. 37, n. 3, p. 569-584, set./dez., 2012. Disponível em: https://periodicos.ufsm.br/reveducacao/article/view/5012/3981. Acesso em: 14 mai. 2020.

BRASIL. Coordenação de Aperfeiçoamento de Pessoal de Nível Superior. Programa de Licenciaturas Internacionais - Portugal. Disponível em:

https://www.gov.br/capes/pt-br/acesso-a-informacao/acoes-e-programas/bolsas/bolsas-e-auxilios-internacion ais/informacoes-internacionais/programas-encerrados-internacionais/licenciaturas-internacionais-portugal Acesso em: 20 jul. 2020.

BRASIL. Ministério da Ciência Tecnologia e Inovação. Painel de controle do programa Ciência sem Fronteiras. Brasília, DF, 2016. Disponível em: http://www.cienciasemfronteiras.gov.br/web/csf/painel-de-controle Acesso em: 22 jul. 2020.

BRASIL. Ministério da Educação. Sinopse estatística do Enade 2016. Disponível em: http://inep.gov.br/web/guest/sinopses-estatisticas-do-enade. Acesso em: 15 set. 2020.

BRITO, Silvia Helena Andrade; RODRÍGUEZ, Margarita Victoria; MACIEL, Carina Elisabeth. Internacionalização da Educação Superior: a questão da mobilidade discente na Universidade Federal de Mato Grosso do Sul, UFMS (2011-2017). Série-Estudos - Periódico do Programa de Pós-Graduação em Educação da UCDB, Campo Grande, p. 185-206, jan./abr., 2020. Disponível em: https://www.serie-estudos.ucdb.br/serie-estudos/article/view/1380/pdf. Acesso em: 14 mai 2020.

CANAN, Silvia Regina; SUDBRACK, Edite Maria; SILVA, Thais Campos da. Construindo cenários de mobilidade acadêmica: o processo de internacionalização em uma universidade comunitária. Série-Estudos Periódico do Programa de Pós-Graduação em Educação da UCDB, Campo Grande, v. 25, n. 53, p. 207-232, jan./abr., 2020. Disponível em:

https://www.serie-estudos.ucdb.br/serie-estudos/article/view/1387/pdf. Acesso em: 14 mai. 2020.

CANUTO, Simone Aparecida. Um olhar científico sobre a relação de intercambio do estudante brasileiro em Portugal. Augusto Guzzo Revista Acadêmica, São Paulo, v. 1, n. 14, p. 115-122, 2014. Disponível em: http://www.fics.edu.br/index.php/augusto guzzo/article/view/239/336. Acesso em: 14 mai. 2020.

CARRILLO, Juan. Searching for "Home" in Dixie: identity and education in the new latin@ south. Educational Studies, London, v. 52, n. 1, p. 20-37, 2016.

CRUZ, Aline Pecorari da. O Programa Erasmus: Paradigma para o Mercosul? Cadernos Jurídicos, Campinas, ano 1, v. 1, n. 2, p. 123-144, 2010.

CUNHA, Maria Isabel da.; RASCHKE, Maria Janine. Mobilidade estudantil e internacionalização: Desafios contemporâneos e qualidade acadêmica. Integração Y Conocimiento, Córdoba, v. 1, n. 8, p. 17-32, 2019. Disponível em: https://revistas.unc.edu.ar/index.php/integracionyconocimiento/article/view/24659/24131. Acesso em: 14 mai. 2020.

DAAD. Sobre o DAAD. Disponível em: https://www.daad.org.br/pt/quem-somos/sobre-o-daad/ Acesso em: 20 de jul. 2020.

DUARTE, Roberto Gonzalez; CASTRO, José Márcio de; CRUZ, Ana Luiza Albuquerque; MIURA, Irene K. O papel dos relacionamentos interpessoais na internacionalização de instituições de ensino superior. Educação em Revista, Belo Horizonte, v. 28, n. 1, p. 343-370, 2012. Disponível em: https://www.scielo.br/j/edur/a/LJrM9T7jn3CYyKCNCt8kSvS/?lang=pt\&format=pdf. Acesso em: 14 mai. 2020 . 
ERASMUS. Sobre o Erasmus+. Disponível em:

https://ec.europa.eu/programmes/erasmus-plus/opportunities/individuals/students/studying-abroad pt Acesso em 20 jul. 2020.

FAGUNDES, Caterine; LUCE, Maria Beatriz; SILVEIRA, Paloma Dias. A qualidade da mobilidade de estudantes de graduação no "Ciências sem Fronteiras". Ensaio: Avaliação e Políticas Públicas em Educação, Rio de Janeiro, v. 27, n. 105, p. 904-927, out/dez. 2019. Disponível em:

https://www.scielo.br/j/ensaio/a/JyRQcQffdL6Kz5XGdN6gkbS/?lang=pt\&format=pdf. Acesso em: 14 maio 2020.

GIL, Antônio Carlos. Métodos e Técnicas de Pesquisa Social. 6. ed. São Paulo: Atlas, 2011.

GUAZZELLI, Maria Elisabete et al. Internacionalização do Ensino Superior e as Instituições de Ensino Privado no Brasil. Abcs Health Sciences, Santo André, v. 40, n. 3, p. 294-299, 2015. Disponível em: https://www.portalnepas.org.br/abcshs/article/view/810. Acesso em: 14 mai. 2020.

JUNIOR, Marcos de Oliveira; MATTOS, Flávio de Freitas. Ciência sem Fronteiras: Experiências discentes na odontologia. Revista Docência do Ensino Superior, Belo Horizonte, v. 7, n. 2, p. 200-218, jul./dez., 2017. Disponível em: https://periodicos.ufmg.br/index.php/rdes/article/view/2287/1426. Acesso em 14 mai. 2020.

KNIGHT, Jane. International Education Hubs: collaboration for competitiveness and sustainability. New Directions for Higher Education, New Jersey, v. 2014, n. 168, p. 83-96, 2014.

KNIGHT, Jane. Internationalization Remodeled: definition, approaches, and rationales. Journal of Studies in International Education, [S.L.], v. 8, n. 1, p. 5-31, 2004.

LAUERMANN, Fani. To go or not to go: the decision to pursue higher education abroad. Advances in Motivation and Achievement, Bingley, p. 177-204, 2012.

LEASK, Betty. Internationalizing the curriculum. 1 ed. New York: Routledge, 2015.

LIMA, Manolita Correia; MARANHÃO, Carolina Machado Saraiva de Albuquerque. O sistema de educação superior mundial: entre a internacionalização ativa e passiva. Avaliação: Revista da Avaliação da Educação Superior, Campinas, v. 14, n. 3, p. 583-610, 2009. Disponível em:

https://www.scielo.br/j/aval/a/5VJDvJnkgsDn9nmwWCCvKbj/?format=pdf\&lang=pt. Acesso em: 14 mai. 2020.

MARTINS-BORGES, Lucienne. Migração involuntária como fator de risco à saúde mental. Revista Interdisciplinar de mobilidade humana, Brasília, v. 21, p. 151-162, 2013. Disponível em: https://www.scielo.br/j/remhu/a/5ybFYzvWhw9K6TXFHY9QVpD/?format=pdf\&lang=pt. Acesso em 14 mai 2020.

MASETTO, Marcos Tarciso. Competência pedagógica do professor universitário. 3 ed. São Paulo: Summus Editorial, 2003.

MURPHY-LEJEUNE, Elizabeth. Student Mobility and narrative in Europe: The new strangers. 1 ed. London: Routledge, 2002.

NOGUEIRA, Maria Alice; AGUIAR, Andrea Moura de Souza; RAMOS, Viviane Coelho Caldeira. Fronteiras desafiadas: a internacionalização das experiências escolares. Educação \& Sociedade, Campinas, v. 29, n. 103, p. 355-376, 2008. Disponível em: https://www.scielo.br/j/es/a/wRW6c47y9swCqicw4qh9wDk/?lang=pt\&format=pdf. Acesso em: 14 mai. 2020 . 
OLIVEIRA, Adriana Leonidas de; FREITAS, Maria Ester de. Motivações para a mobilidade acadêmica internacional: a visão de alunos e professores universitários. Educação em Revista, Belo Horizonte, v. 32, n. 3, p. 217-246, 2016. Disponível em:

https://www.scielo.br/j/edur/a/dpPjRHVbBtHfhGS574xnxmG/?format=pdf\&lang=pt. Acesso em: 14 mai. 2020.

OLIVENCIA, Juan José Leiva. La interculturalidad en el contexto universitario a través de las voces de estudiantes inmigrantes. Revista Electrónica Interuniversitaria de Formación del Profesorado, Murcia, v. 17, n. 2, p. 155-166, 2014. Disponível em: https://revistas.um.es/reifop/article/view/155/162031. Acesso em: 14 mai. 2020.

RIBEIRO, José Antonio Bicca et al. Mobilidade estudantil e internacionalização: o programa ciência sem fronteiras em uma universidade no sul do brasil. In: CUNHA, Maria Isabel da. Internacionalização e democratização: uma tensão na qualidade da educação superior? São Leopoldo: Oikos, 2016. p. 77-97.

SANTOS, Boaventura de Sousa. A Universidade no século XXI. 3 ed. São Paulo: Cortez Editora, 2011.

SEIXAS, Ana Maria. Políticas educativas para o ensino superior: a globalização neoliberal e a emergência de novas formas de regulação estatal. In: STOER, Stephen Ronald; CORTESÃO, Luiza; CORREIA, José Alberto (orgs.). Transnacionalização da educação: da crise da educação à "educação" da crise. Porto: Afrontamento, 2001.p. 211-239.

SOUZA, Marina et al. Internacionalização do ensino superior: Para além da mobilidade internacional. Sensos-e, Porto, v. 6, n. 3., p. 28-38, 2019. Disponível em: https://recipp.ipp.pt/bitstream/10400.22/17393/1/ART CIETI_MAS 2019.pdf. Acesso em 14 mai. 2020.

SOUZA, Nayara Christine; PALAFOX, Gabriel Humberto Muñoz. Análise do Programa de Licenciatura Internacional - PLI, no contexto da internacionalização da educação superior. Poiésis - Revista do Programa de Pós-Graduação em Educação, Tubarão, v. 10, n. 18, p. 417-430, 2016. Disponível em: http://www.portaldeperiodicos.unisul.br/index.php/Poiesis/article/view/3105/2927. Acesso em: 14 mai. 2020.

UFPB. Universidade Federal da Paraíba. Sistema Integrado de Gestão de Atividades Acadêmicas . Disponível em: https://sigaa.ufpb.br/sigaa/link/public/extensao/visualizacaoAcaoExtensao/1607. Acesso em: 20 jul. 2020.

VIEIRA, Maria Manuel. Das disposições cosmopolitas à mobilidade como competência? Ensino superior, Programa Erasmus e mobilidade estudantil. Educação em Foco, Belo Horizonte, v. 18, n. 26, p. 15-42, 2015. Disponível em: https://revista.uemg.br/index.php/educacaoemfoco/article/view/1036/786. Acesso em: 14 mai. 2020.

WIT, Hans de. Internationalization of Higher Education in the United States of America and Europe: a historical, comparative, and conceptual analysis. Westport: Greenwood Press, 2002.

ZAGO, Nadir. Do acesso à permanência no ensino superior: percursos de estudantes universitários de camadas populares. Revista Brasileira de Educação, Campinas, v. 11, n. 32, p. 226-237, 2006. Disponível em: https://www.scielo.br/j/rbedu/a/wVchYRqNFkssn9WqQbj9sSG/?format=pdf\&lang=pt. Acesso em: 14 mai. 2020. 


\section{NOTAS DE AUTOR}

\section{AGRADECIMENTOS}

Agradecemos aos estudantes que aceitaram participar do estudo e contribuíram com as informações.

FINANCIAMENTO - Não se aplica.

CONSENTIMENTO DE USO DE IMAGEM - Não se aplica.

\section{APROVAÇÃO DE COMITÊ DE ÉTICA EM PESQUISA}

O estudo foi aprovado pelo Comitê de Ética em Pesquisa da Escola Superior de Educação Física da Universidade Federal de Pelotas (ESEF/UFPel), através do parecer nº 4.033.320 de 18/maio/2020.

CONFLITO DE INTERESSES - Não há conflitos de interesses.

\section{LICENÇA DE USO}

Os autores cedem à Motrivivência - ISSN 2175-8042 os direitos exclusivos de primeira publicação, com o trabalho simultaneamente licenciado sob a Licenca Creative Commons Attribution Non-Comercial ShareAlike (CC BY-NC SA) 4.0 International. Esta licença permite que terceiros remixem, adaptem e criem a partir do trabalho publicado, desde que para fins não comerciais, atribuindo o devido crédito de autoria e publicação inicial neste periódico desde que adotem a mesma licença, compartilhar igual. Os autores têm autorização para assumir contratos adicionais separadamente, para distribuição não exclusiva da versão do trabalho publicada neste periódico (ex.: publicar em repositório institucional, em site pessoal, publicar uma tradução, ou como capítulo de livro), com reconhecimento de autoria e publicação inicial neste periódico, desde que para fins não comerciais e compartilhar com a mesma licença.

\section{PUBLISHER}

Universidade Federal de Santa Catarina. Programa de Pós-Graduação em Educação Física. LaboMídia - Laboratório e Observatório da Mídia Esportiva. Publicado no Portal de Periódicos

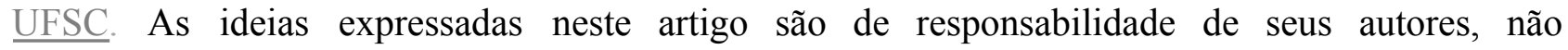
representando, necessariamente, a opinião dos editores ou da universidade.

\section{EDITORES}

Mauricio Roberto da Silva, Giovani De Lorenzi Pires, Rogério Santos Pereira.

\section{EDITOR DE SEÇÃO}

Bianca Poffo.

\section{REVISÃO DO MANUSCRITO E METADADOS}

João Caetano Prates Rocha; Keli Barreto.

\section{HISTÓRICO}

Recebido em: 11 de novembro de 2020.

Aprovado em: 04 de maio de 2021. 